\title{
WHY SOME BIM TOOL USERS DO NOT THINK OF THEMSELVES AS BIM USERS - A PRELIMINARY STUDY
}

\author{
Yongshin $\mathrm{An}^{1}$, Ghang Lee ${ }^{2}$
}

\begin{abstract}
Some people claim that they are not users of building information modeling (BIM) even when they use BIM tools. This study investigates why some non-BIM users believe that they are not BIM users by analyzing their perceptions of BIM. To this end, a survey was conducted with BIM and non-BIM users in the Republic of Korea. The survey consisted of questions about the perception of BIM and non-BIM users toward BIM use, process, organization and policy. The results show that suspicious non-BIM users account for $65 \%$ of non-BIM users. The analysis of the survey reveals that non-BIM users who actually use BIM tools have a higher expectation of the level of overall BIM adoption than BIM users have. They believe that they are not BIM users, because they currently deploy only basic BIM uses that do not require a high level of collaboration, and they do not have a BIM specialist (BIM manager) in their group. Further research on the global view of BIM users is recommended.
\end{abstract}

Keywords: BIM (Building Information Modeling), BIM use, BIM process, BIM organization, suspicious non-BIM user, PPTP framework

\section{INTRODUCTION}

A previous study conducted by the authors found that over half of the people who claim to be non-BIM users actually use BIM tools (An and Lee 2016). This study refers to such people as "suspicious non-BIM users." The purpose of this study is to identify why these suspicious non-BIM users regard themselves as non-BIM users. Since the mid2000s, quite a few studies have been conducted on non-BIM users, mostly focusing on attitudes toward BIM and reasons why people do not use BIM. None of these studies, however, has assumed that non-BIM users actually use BIM tools, although BIM tool users have been generally perceived as BIM users.

BIM is often defined as the process of generating, managing, and (re)using data through the lifecycle of a project or of the data itself (CRC 2009, NIBS 2007, GSA 2003, AIA 2007, ISO 2010, Eastman et al. 2014, Lee et al. 2006). Based on this definition, we conducted a survey to understand the circumstances in which respondents perceived themselves to be BIM users or non-BIM users from the perspective of BIM process, organization, use, and policy, based on the process, people, technology, and policy (PPTP) framework.

The PPT or the PPTP (including policy) framework has been widely used in business process renovation across industries since the 1980s. Since the late 2000s, this PPTP framework has begun to be applied in defining BIM. Dave et al. (2008) reviewed the use

1 Graduate Research Assistant, Architectural Engineering, Yonsei University, Seoul, Republic of Korea, sara4938_@naver.com

2 Corresponding author, Professor, Architectural Engineering, Yonsei University, Seoul, Republic of Korea, glee@yonsei.ac.kr 
of the PPT framework in the application of ICT and BIM in construction. About the same time, buildingSMART International organized its subgroups (such as user group, implementation support group, process room, product room, and regulatory room) based on the PPTP framework. Succar (2009) defined the next generation of BIM as Integrated Design and Delivery Solutions, which involves an interaction of people (human or organizational factors), process, and technology. Since then, the PPT or PPTP framework-or minor variations of this framework-have been used widely in defining BIM.

As a preliminary study, we conducted a survey with 61 people working in the architecture, engineering, and construction (AEC) industry in the Republic of Korea, based on the PPTP framework.

This paper reports the findings in the following order. It first reviews previous studies on BIM use, process, organization and policy. Based on the review, the composition of the survey and the analysis of its results are presented. Finally, we discuss the reasons why suspicious non-BIM users regard themselves as non-BIM users.

\section{PREVIOUS STUDIES}

This section reviews previous studies from three aspects, namely, BIM use (technology), process, and organization (including people and policy), based on the PPTP framework. In addition, it reviews previous studies on BIM users and non-BIM users.

\subsection{BIM use}

Many studies have been conducted to understand how BIM is used in the industry, the most representative of which is the SmartMarket Report BIM series (Dodge Research and Analytics 2017). Pennsylvania State University (Penn State) consolidated the BIM uses in previous studies into 25 types of BIM use according to project phase (Messner et al. 2010, Azhar 2011). Each BIM use was described using a definition and examples.

In 2013, the Penn State team proposed another classification for BIM use, based on five purposes-gathering, generating, analyzing, communicating, and realizing (Kreider and Messner 2013). Each purpose has 18 subcategories, and each subcategory includes BIM uses, objectives, and synonyms of BIM uses. In comparison to the above phasebased classification, this purpose-based classification is not widely used because it does not align well with the general project process. This study also uses the Penn State's phase-based classification of BIM uses to define BIM uses in the survey.

\subsection{BIM process}

Succar (2009) referred to the requirements for the next stage in the BIM maturity stages as BIM steps. Among these BIM steps, process steps consist of leadership, infrastructure, human resources, products, and service. To move to the next BIM maturity stage, these process items should be satisfied. Khosrowshahi and Arayici (2012) added BIM process elements to the BIM implementation stages according to the level of collaboration. The first stage (object-based modeling) has asynchronous communication, the second stage (model-based collaboration) has asynchronous communication and model-based sharing information, and the third stage (integrated practice) has streamlined lean process, synchronized communication, and multi-server collaboration. Dawood and Vukovic (2015) classified the process according to the work stream in each phase. The process involves identifying the work stream and standards for each stream, manual, setting 
LOD (level of development), setting LOI (level of information), document process, modeling standard, and contractual arrangements. This study defined the BIM process according to the level of collaboration based on Khosrowshahi and Arayici (2012).

\subsection{BIM organization}

Owen (2009) insists that a project team should have qualified people, business culture, and support management system. Regarding the policy perspective, Succar (2009) states that contracts, regulations, and research/education are components of a necessary policy step in progressing to the next BIM implementation stage. The policy step contains guideline, standards, etc.

Other studies propose categories that blur the boundaries between people and policy. Dawood and Vukovic (2015) argue that the people are the crucial elements of the policy and that the two categories have a strong association with each other. According to research, the organization needs not only organizational elements such as well-educated human resources, leadership, and teamwork but also support systems like modeling process standards, model ownership, and roles and responsibilities. Ali et al. (2015) classify BIM maturity stages as non-existent, initial, managed, defined, qualitatively managed, and optimizing, according to the status of the organization. Each phase also includes policy-related content such as goals, execution plan, skilled people, and guidelines.

In the review, it is hard to consider the two categories (people and policy) as being completely separate. Therefore, this study uses organization as a container for the two categories

\subsection{BIM users and non-BIM users}

Surveys for BIM perception have been conducted in several organizations. McGraw Hill construction annually implements a survey of BIM adoption status, which includes an investigation of BIM perception. This survey analyzes why non-BIM users do not use BIM, the influence of BIM use and comparison of perception among BIM users and nonBIM users. The survey, however, overlooks the fact that some non-BIM users actually utilize BIM tools (Dodge Research and Analytics 2017). The national BIM survey also investigates and compares BIM perceptions and it has found that the expectations of non-BIM users are higher than those of BIM users (NBS 2014, NBS 2015, NBS 2016). Unlike non-BIM users, BIM users give higher values to basic BIM uses-which people can do alone-like 3D visualization and give lower values to complex functions-which require collaboration with others-such as cost estimation.

A survey on BIM adoption in the Republic of Korea also reveals that some BIM tool users consider themselves as non-BIM users (An and Lee 2016), raising the question of whether the non-BIM users investigated in several studies really non-BIM users. To define users' perception of BIM projects, questions were created based on the studies mentioned in the above literature review.

\section{RESEARCH METHOD}

\subsection{Composition of the survey}

To investigate why suspicious non-BIM users do not consider themselves to be BIM users, the study group is composed of people working in the construction industry in the Republic of Korea. The survey consists of three parts, as presented in Table 1. Each part 
consists of three elements: BIM use, BIM process, and BIM organization. The survey starts with a question about choosing BIM tools and their use in order to distinguish suspicious non-BIM users. To measure the perceptions of suspicious non-BIM users, the questions explored minimum requirements of BIM projects. The questions also included the presence of the BIM specialist in the project team to compare BIM users and suspicious non-BIM users.

Table 1: Composition of the survey

\begin{tabular}{ccc}
\hline Category & Questions & References \\
\hline & Which BIM tools do you use on & \\
BIM Use & your projects and their use? & (Messner et al. 2010, Azhar 2011) \\
& What are the three minimum ways & \\
& of using BIM? & \\
BIM Process & What are the three minimum & (Khosrowshahi and Arayici 2012, Succar \\
& process requirements for BIM? & 2009, Dawood and Vukovic 2015) \\
BIM & $\begin{array}{c}\text { What are the three minimum } \\
\text { organizational requirements for }\end{array}$ & \\
Organization & BIM? & (Owen 2009, Succar 2009, Dawood and \\
& $\begin{array}{c}\text { Does your project team have a BIM } \\
\text { manager or specialist? }\end{array}$ & \\
\hline
\end{tabular}

\subsection{The BIM perception scores}

Based on the literature review, the BIM perception score was developed by categorizing BIM uses, processes, and organizations into three levels. The detailed score structure is presented in Table 2. The use category refers to the previous literature review. The minimum uses for BIM come from the many definitions (Messner et al. 2010, Azhar 2011, Kreider et al. 2010, Kreider and Messner 2013), and they are divided into three BIM maturity stages (Khosrowshahi and Arayici 2012). The BIM uses in which people can use it alone were assigned to a lower stage, and the BIM uses that require collaboration were assigned to a higher stage. The items in the process category are also classified into three stages using the four approaches to BIM: lonely BIM, shy BIM, friendly BIM, and social BIM (McCallum 2011). The organization and policy category refers to case studies. Guidelines and standards are the basic requirements for BIM. After these requirements are met, the project team has BIM experts internally as well as external BIM experts (Zakaria et al. 2013). 
Table 2: The BIM perception score

\begin{tabular}{|c|c|c|}
\hline Perception stage & Category & Minimum requirements \\
\hline $\begin{array}{l}\text { Stage } 1 \\
\text { (1 point) }\end{array}$ & $\begin{array}{c}\text { Use } \\
\text { Process } \\
\text { Organization }\end{array}$ & $\begin{array}{l}\text { 3D visualization, BIM model with attributes, design } \\
\text { authoring, document extraction } \\
\text { Sharing building information with team members } \\
\text { Having BIM guide, BIM execution plan, standard of } \\
\text { collaboration on a project }\end{array}$ \\
\hline $\begin{array}{c}\text { Stage } 2 \\
\text { (2 points) }\end{array}$ & $\begin{array}{c}\text { Process } \\
\text { Organization }\end{array}$ & $\begin{array}{l}\text { 4D scheduling simulation, 5D cost estimation, } \\
\text { Clash detection, design review } \\
\text { Collaborating with team members using BIM models, } \\
\text { Coordinating a project using BIM models, } \\
\text { Using a server to share building information } \\
\text { Having a BIM team on a project or company }\end{array}$ \\
\hline $\begin{array}{c}\text { Stage } 3 \\
\text { (3 points) }\end{array}$ & $\begin{array}{l}\text { Process } \\
\text { Organization }\end{array}$ & $\begin{array}{l}\text { Engineering analysis, BIM based-project management } \\
\text { Integrated project delivery, } \\
\text { Integrated BIM and off-site fabrication process, } \\
\text { Integrated BIM and construction automation process } \\
\text { Having a BIM specialist on a team or project }\end{array}$ \\
\hline
\end{tabular}

The average of a BIM use score, BIM processes score, and BIM organization score is regarded as the total BIM perception score. Each item was scored using a 1 to 3 grading scale: 1 (lower level), 2 (medium level), 3 (high level). The BIM perception scores are an average of these items. After collecting the data, the results were analyzed using a statistical analysis.

\section{SURVEY RESULTS}

Among the 61 respondents, 34\% were BIM users and $66 \%$ were non-BIM users. The sample was taken from contact information in the construction related organization. This group includes people who work in the architecture, engineering, and construction (AEC) industry and BIM consultant companies. Sixty-five percent of non-BIM users using BIM tools are considered to be suspicious non-BIM users because they actually use BIM tools. This section introduces a composition of the BIM perception score to evaluate people's perception. Based on the BIM perception score, we investigate BIM use, process, organization, and policy. We also explain why suspicious non-BIM users consider themselves to be non-BIM users.

\subsection{The BIM perception scores}

The t-test was conducted to compare scores between BIM users and suspicious nonBIM users. Although there was a little difference between the two groups in the BIM use, process, and organization and policy scores, the result using the t-test revealed that the difference within each category was not significant. The difference between the total BIM perception scores (the average of the three scores) of BIM users and suspicious nonBIM users, however, was statistically significant ( $\mathrm{p}$-value $=0.034<0.05$ ). The total BIM perception scores were 5.388 points for BIM users and 5.878 points for suspicious nonBIM users. It is inferred that the expectation of suspicious non-BIM users toward BIM is higher than that of the BIM users. These results are given in Table 3. 
Table 3: T-test for a BIM perception score

\begin{tabular}{ccccccccc}
\hline & \multicolumn{2}{c}{ Total score } & \multicolumn{2}{c}{ Use score } & \multicolumn{2}{c}{ Process score } & \multicolumn{2}{c}{$\begin{array}{c}\text { Organization and } \\
\text { policy score }\end{array}$} \\
& Mean & SD & Mean & SD & Mean & SD & Mean & SD \\
\hline $\begin{array}{c}\text { Suspicious non- } \\
\text { BIM users }\end{array}$ & 5.878 & 0.771 & 5.557 & 1.387 & 7.000 & 1.264 & 5.076 & 1.016 \\
BIM users & 5.388 & 0.751 & 5.119 & 1.023 & 6.285 & 1.454 & 4.761 & 1.338 \\
t-value(p) & $2.187(0.034)$ & $1.206(0.234)$ & $1.800(0.079)$ & $0.917(0.364)$ \\
\hline
\end{tabular}

\subsection{BIM uses}

In spite of statistically insignificant scores among BIM users and suspicious non-BIM users, there was a marked contrast between the two groups. The results are presented in Figure 1.

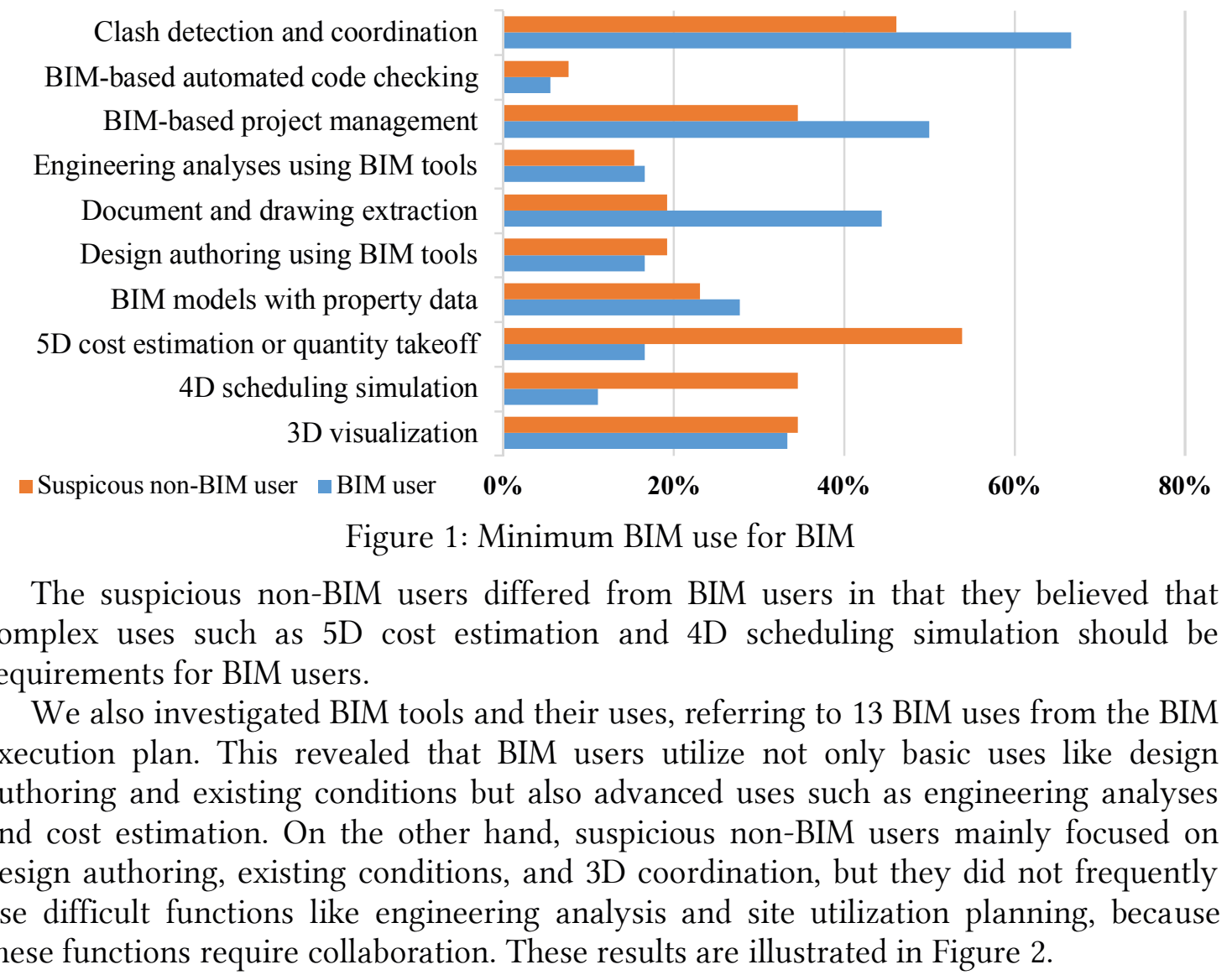




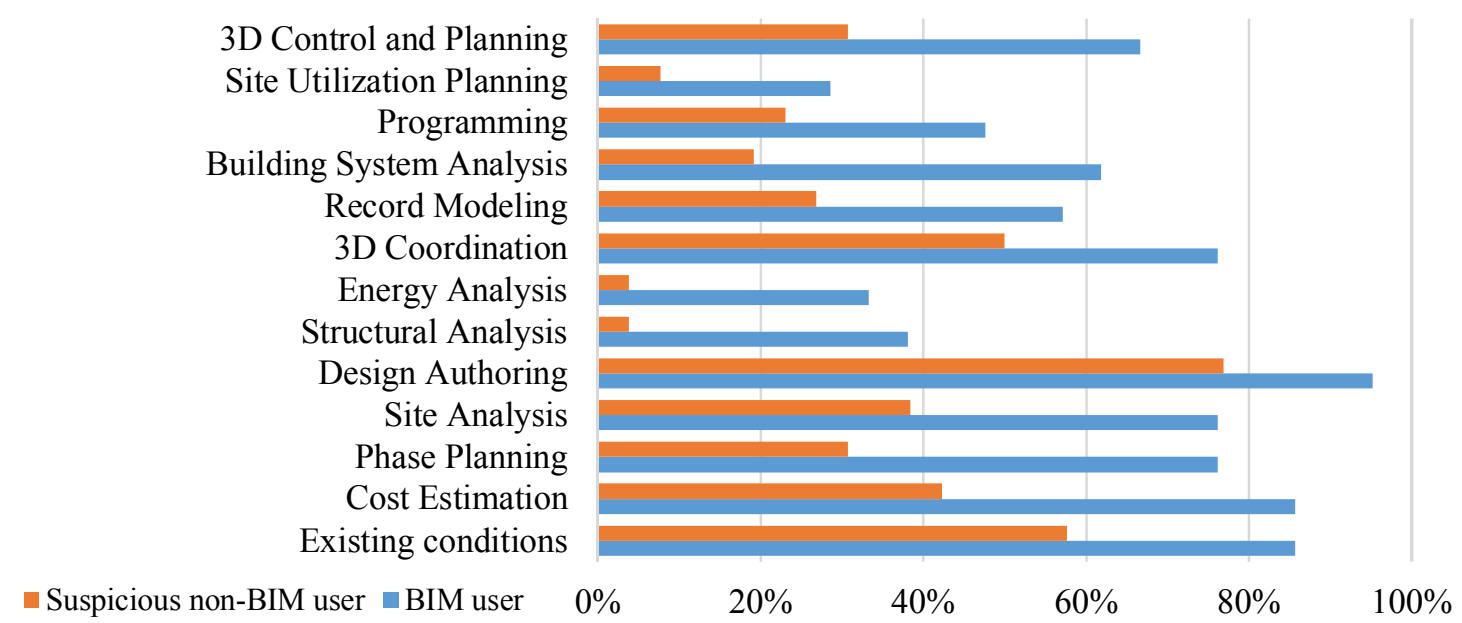

Figure 2: BIM uses of BIM software

\subsection{BIM process, organization, and policy}

The scores of suspicious non-BIM users (average 7 points) in the BIM process category are higher than those of BIM users (average 6.28 points), but are not statistically significant. As can be seen from the results, the process does not solely explain why suspicious non-BIM users do not consider themselves as BIM users.

The BIM organization score also has a statistically insignificant value between two groups: suspicious non-BIM users averaged 5.07 points and BIM users averaged 4.76 points. This means that the organizational elements do not have a strong influence on the perceptions of suspicious non-BIM users.

Nevertheless, when people were asked whether they have a BIM manager in the current team, $86 \%$ of BIM users and $27 \%$ of suspicious non-BIM users answered that they have BIM managers. We also conducted correlation analysis between the groups and the presence of the BIM manager and we found a strong correlation: Pearson value was 0.586 and p-value was 0.000 . Through this result, it can be inferred that suspicious nonBIM users do not think themselves as BIM users because they do not have BIM specialists in their organization.

\section{CONCLUSION}

This study shows that $65 \%$ of non-BIM users actually use BIM tools. We investigated why these "suspicious non-BIM users" perceive themselves as non-BIM users and explored the minimum requirements for determining BIM and BIM users through a survey with 61 AEC professionals in the Republic of Korea.

We concluded that these suspicious non-BIM users do not claim that they are BIM users due to the following reasons: 1) their total BIM perception score is higher than that of BIM users; 2) they think that even complex BIM uses such as 5D cost estimation and 4D scheduling simulation are the minimum requirements for BIM; 3) they currently use only basic functions such as 3D coordination and design authoring using BIM tools; and 4) they have a higher probability than BIM users of not having a BIM manager in their project team.

The main contribution of this research is that it confirms that simply using BIM tools does not suffice for people to be actual BIM users; they must use BIM in a collaborative BIM environment. The findings imply that the term BIM user should be used with care 
in future surveys and studies. A limitation of this study is that this survey was conducted only in South Korea. Further research is required to explore what determines BIM and BIM users from a global perspective. We invite fellow researchers to collaborate on international research on this topic.

\section{REFERENCES}

AIA. (2007). A working Definition: Integrated Project Delivery. McGraw Hill Construction.

Ali, A., Alain, A., Daniel, F. and Michael, L. (2015). BIM maturity assessment and certification in construction project team selection. PhD Thesis. École de technologie supérieure.

An, Y. and Lee, G. (2016). Survey Results on BIM Adoption in Korea. The BIM buildingSMART Korea.

Azhar, S. (2011). Building Information Modeling (BIM): Trends, Benefits, Risks, and Challenges for the AEC Industry. Leadership and Management in Engineering, 11, 241-252.

CRC. (2009). National Guidelines for Digital Modeling. Cooperation Research Centre for Construction innovation, 1.

Dave, B., Koskela, L., Kagioglou, M. and Bertelsen, S. (2008). A critical look at integrating people, process and information systems within the construction sector. 16th Annual Conference of the International Group for Lean Construction. Manchester, 795-808.

Dawood, N. and Vukovic, V. (2015). Whole Lifecycle Information Flow Underpinned by BIM: Technology, Process, Policy and People. 2nd International Conference on Civil and Building Engineering Informatics, Tokyo, Japan, April 22-24.

Dodge Research and Analytics. (2017). SmartMarket Reports Webpage [Online]. Available: https://analyticsstore.construction.com/index.php/markettrends/smartmarket-reports.html.

Eastman, C., Teicholz, P., Sacks, R. and Liston, K. (2014). BIM Handbook: A Guide to Building Information Modeling for Owners, Managers, Designers, Engineers and Contractors. John Wiley \& Sons, Inc., 2.

GSA. (2003). BIM Guide Overview. Public Buildings Service.

ISO. (2010). ISO-DIS 29481-1 Building Information Models-Information Delivery Manual.

Khosrowshahi, F. and Arayici, Y. (2012). Roadmap for implementation of BIM in the UK construction industry. Engineering, Construction and Architectural Management, 19, 610-635.

Kreider, R. and Messner, J. (2013). The Uses of BIM: Classifying and Selecting BIM Uses. The Pennsylvania State University.

Kreider, R., Messner, J. and Dubler, C. (2010). Determining the Frequency and Benefit of Applying BIM for Different Purposes on Building Projects. 6th International Conference on Innovation in Architecture, Engineering and Construction (AEC).

Lee, G., Sacks, R. and Eastman, C. M. (2006). Specifying parametric building object behavior (BOB) for a building information modeling system. Automation in Construction, 15, 758-776.

Mccallum, B. (2011). The Four Approaches to BIM [Online]. Available: http://bim4scottc.blogspot.kr/2012/10/the-four-approaches-to-bim.html. 
Messner, J., Anumba, C., Dubler, C., Goodman, S., Kasprzak, C., Kreider, R., Leicht, R., Saluja, C. and Zikic, N. (2010). BIM Project Execution Planning Guide. The Computer Integrated Construction Research Program.

NBS. (2014). National BIM Report 2014. National BIM survey. Newcastle, England.

NBS. (2015). National BIM Report 2015. National BIM survey. Newcastle, England.

NBS. (2016). National BIM Report 2016. National BIM survey. Newcastle, England.

NIBS. (2007). National Building Information Modeling Standard. National Institute of Building Sciences.

Owen, R. (2009). White Paper on IDDS Integrated Design and Delivery Solutions, Publication 328. C1B, Rotterdam, The Netherlands.

Succar, B. (2009). Building information modelling framework: A research and delivery foundation for industry stakeholders. Automation in Construction, 18, 357-375.

Zakaria, B., Ali, Z. M., Haron, N. T., Marshall-ponting, A. and Hamid, A. A. A. (2013). Exploring the adoption of Building Information Modelling (BIM) in the Malaysian construction industry: A qualitative approach. International Journal of Research in Engineering and Technology, 2. 